\title{
O ESTÁGIO EXTRACURRICULAR EM CIRURGIA ONCOLÓGICA: O OLHAR DO ACADÊMICO DE MEDICINA.
}

\author{
THE EXTRACURRICULAR STAGE IN ONCOLOGICAL SURGERY: THE VIEW OF \\ THE MEDICINE ACADEMIC.
}

\author{
João Marcos Gomes, Verônica Félix, Pamela Donato, Ana Carolina, Gunnar Taets
}

Universidade Federal do Rio de Janeiro (UFRJ) - Campus Macaé

\begin{abstract}
This is a descriptive study of an experience report on an extracurricular internship carried out at a Public Hospital in the city of Curitiba-PR. It aims to describe and discuss the practice of extracurricular internships in the medical course and its impact on medical-academic training. The voluntary internship represents an important tool in the medical training process, as it provides the development of different skills and competences in different academic training. The opportunity to bring the student closer to different extracurricular practices, in addition to those offered by the university which is inserted, allows him to carry out his theoretical scientific knowledge learned during his training process. Furthermore, it provides stimulating learning, capable of developing skills and competences ranging from research to assistance. With this, it can be said that the practice of voluntary internships are essential tools for the medical student to produce a more accurate view of the clinical reality, not only basing their previous theoretical-practical knowledge, but also obtaining new perspectives and learning.
\end{abstract}

Keywords: Clinical Clerkship; medical education; Unified Health System; Oncology Service, Hospital; Surgical Oncology.

\section{Resumo}

Trata-se de um estudo descritivo de um relato de experiência sobre um estágio extracurricular realizado em um Hospital Público da cidade de Curitiba-PR. Tem por objetivo descrever e discutir sobre a prática de estágios extracurriculares no curso de medicina e seu impacto na formação médico-acadêmica. $O$ estágio voluntário representa uma importante ferramenta no processo de formação médica, pois proporciona o desenvolvimento de diversas habilidades $e$ competências na formação acadêmica diferenciada. A oportunidade de aproximar $o$ discente de práticas extracurriculares diferentes, além das ofertadas pela universidade o qual está inserido, permite que o mesmo execute seus conhecimentos teóricos científicos aprendidos no decorrer do seu processo de formação. Ademais, proporciona uma aprendizagem estimuladora, capaz de desenvolver habilidades e competências que vão desde a pesquisa à assistência. Com isso, pode-se afirmar que a prática dos estágios voluntários são ferramentas essenciais para $o$ estudante de medicina produzir uma visão mais acurada da realidade clínica, não só fundamentando seu conhecimento teóricoprático pregresso, mas também obtendo novos olhares e aprendizados.

Palavras-chave: Estágio clínico; educação médica; Sistema Único de Saúde; Serviço Hospitalar de Oncologia; Oncologia Cirúrgica. 


\section{Introdução}

Apesar dos avanços ocorridos no âmbito da radioterapia e quimioterápicos, a cirurgia oncológica ainda se configura como um dos principais cuidados, podendo ser preventiva, diagnóstica, curativa, adjuvante aos demais tratamentos, ou paliativa; por esse motivo, tal especialidade assume um importante papel na redução da mortalidade por câncer ${ }^{1}$. Entretanto, o relatório "Global cancer surgery: delivering safe, affordable, and timely cancer surgery" 2, concluiu que são poucos os pacientes que possuem acesso a esse tipo de cirurgia. O supracitado ocorre devido a falhas na formação acadêmica e de mais cirurgiões.

A fim de suprir déficits na formação médica, adquirir experiência clínica, desenvolver e agregar habilidades, opta-se, sobretudo, pela inserção em ligas acadêmicas e pela prática de estágios extracurriculares ${ }^{3}$. Ambas atividades se embasam na possibilidade do discente atuar em diferentes cenários de ensino-aprendizagem, além de prepará-lo para atuar nas principais demandas dos serviços de saúde ${ }^{4}$.

O Curso de Medicina da Universidade Federal do Estado do Rio de Janeiro (UFRJ) do Campus Macaé, em seu Projeto pedagógico, conforme as propostas das Diretrizes Curriculares Nacionais do Curso de Graduação em Medicina, tem como propósito formação de profissionais médicos, qualificados com enfoque técnico-científico, ético e humanista. Visando que esses futuros profissionais sejam capazes de gerar e disseminar conhecimentos científicos e práticos, que expressem efetivo compromisso com a melhoria do atendimento às necessidades de saúde da sociedade brasileira, ademais, que contribuam para o desenvolvimento de elevados padrões de excelência no exercício da medicina.

Nesse contexto, revela-se a Liga Acadêmica de Oncologia de Macaé (LAOMAC), uma entidade composta por alunos e professores colaboradores de diferentes áreas e cursos, com a finalidade de promover ações de pesquisa, ensino e extensão de maneira multi e interdisciplinar. A participação na liga garante que o tripé ensino-pesquisa-extensão não se dissocie, e que os acadêmicos possam consolidar os conhecimentos vistos no currículo regular da Universidade. Vale mencionar que a LAOMAC possui um estatuto, que desempenha a função de documento norteador das ações. Ademais, está vinculada ao Comitê Brasileiro de Ligas de Cancerologia (COBRALC).
O COBRALC constitui-se como a confluência entre as Ligas de Cancerologia do Brasil, objetiva a construção do conhecimento de maneira coletiva, viabilizando trocas de experiências, e a integração entre os discentes. Diante disso, são realizados programas de intercâmbios em centros oncológicos, sob orientação de médicos da respectiva equipe no hospital. Além de demasiada relevância no âmbito profissional, acadêmico e intelectual, a imersão em um contexto distinto provê uma vivência de grande valor.

Dessarte, o presente trabalho objetiva relatar a experiência sobre o estágio extracurricular voluntário em cirurgia oncológica realizado por estudantes de Medicina.

\section{Metodologia}

Trata-se de um estudo descritivo, um relato de experiência que se caracteriza por uma compreensão singular da realidade vivenciada pelo estagiário voluntário durante os dias de estágio. 0 presente trabalho descreve parte das vivências do discente durante o Estágio, ocorrido no período de 6 a 10 de janeiro de 2020, com carga horária de 40 horas.

O estágio foi realizado no Setor de Oncologia Cirúrgica de um Hospital Público da Cidade de Curitiba, Sul do Brasil, que é referência no tratamento de câncer no sul do país, atendendo pacientes de todo o Brasil, só no ano de 2009 foram mais de 26.000 pacientes.

\section{Resultados}

Todo estágio realizado é de suma importância para a formação acadêmica de graduandos, pois conhecendo a realidade brasileira das universidades públicas, muitas vezes a parte prática pode ficar, de certa forma, comprometida e o aluno sem vivências em determinadas especialidades, como é o caso da oncologia.

Sob essa ótica, estágios extracurriculares atuam de maneira complementar ao ensino regular oferecido pelas universidades no curso de medicina. A fim de direcionar e estabelecer um vínculo entre o aluno que deseja realizar esse estágio e a instituição que oferta a vaga, comitês, associações e ligas são essenciais. Dessa forma, um programa de vínculo com a COBRALC torna-se relevante para que alunos tenham contato com a área da oncologia e suas dinâmicas ainda na graduação, podendo ser de suma importância 
durante a tomada de decisão sobre qual especialidade seguir. Ademais, mesmo que o aluno não siga a especialidade oncológica, a experiência Ihe dará uma noção maior sobre condutas médicas, aconselhamentos clínicos e acolhimento humanizado.

Durante o estágio, foi possível conhecer o atendimento dentro de um hospital de referência no tratamento de câncer no Brasil, e que conta com uma estrutura diferenciada dentro da saúde pública Brasileira. A equipe multidisciplinar que existe na instituição onde o estágio foi realizado é capacitada para o atendimento humanizado dentro das possibilidades de tratamento que 0 Sistema Único de Saúde (SUS) oferece. Perceber, durante o estágio, que os pacientes podem contar com o apoio multidisciplinar de qualidade, é gratificante para o estudante de medicina em sua formação acadêmica.

Os pacientes quando chegam neste hospital já receberam o diagnóstico oncológico. Muitos apresentam-se abalados com a notícia e assustados com todo o tratamento conhecido como árduo e desgastante, e poucos são aqueles que ingressam no tratamento de forma confiante, por isso, se faz necessário um acolhimento atento e responsável por esclarecer as dúvidas demonstrando para o paciente que o melhor possível será feito.

Sob a supervisão dos preceptores, realizou-se o atendimento a pacientes oncológicos e as topografias tumorais encontradas foram: bexiga, próstata, pulmão, fígado, uretra e útero. $\mathrm{O}$ atendimento ambulatorial de urologia, ginecologia e tórax demonstrou ser importantíssimo para a apreensão do curso da doença, juntamente com os exames laboratoriais e de imagem, a evolução do paciente e a conduta tomada.

A participação no ambulatório de acolhimento de pacientes clínicos e cirúrgicos, e em cirurgias com preceptores especialistas e residentes, mostra a importância da passagem de conhecimento que deve existir dentro desse sistema de formação. Entrar em campo cirúrgico, como apoio ou somente observando, oferece a oportunidade de relembrar conceitos de técnica operatória e solidificação do conhecimento teórico-prático. Dentre os procedimentos assistidos, cita-se: cistoscopia, drenagem de tórax com biópsia de pleura, orquiectomia e broncoscopia com lavado pulmonar.
A relação construída, mesmo que temporária, entre estagiários e residentes de outras partes do Brasil enriquece as parcerias dentro do trabalho e permite a troca de experiências sobre a realidade de universidades brasileiras, tanto públicas quanto privadas, além de proporcionar uma troca interpessoal, que vai desde receber conselhos quanto às residências e mercado de trabalho dentro da área da medicina.

Além do conhecimento acadêmico que essa experiência proporcionou, existe um saber subjetivo, o qual não é possível aprender nos livros: a comunicação com o paciente, as situações apresentadas por eles, que somente a vivência prática é capaz de ensinar. Dentro desse contexto, o estágio é capaz de tornar o conhecimento teórico e prático significativos e transformadores.

Diante da relevância profissional e intelectual que a realização de um estágio pode proporcionar, além da oportunidade de crescimento educacional, pessoal e cultural, a escolha por participar do programa Estágio Voluntário, oferecido pelo COBRALC em parceria com a LAOMAC, apresentouse como um grande desafio e estímulo. Estar inserido num contexto totalmente novo $e$ desconhecido, lidando com uma dinâmica nova da rotina prática, estabelecendo novas relações interpessoais, certamente proporcionou uma experiência entusiasmante e desafiadora.

\section{Discussão}

A construção acadêmica, transpassada por um processo de educação popular em saúde de caráter interativo e ativo, como sugere a pedagogia transformadora Paulo Freire ${ }^{6}$ é de suma importância. Nesse cenário, as ligas acadêmicas constituem alternativas que estimulam e levam ao compartilhamento de experiência entre profissionais já formados e os ainda em formação.

Além disso, o currículo médico brasileiro, destacase pelo enfoque hospitalocêntrico e tecnicista, os conteúdos são transmitidos de forma fragmentada pelas inúmeras especialidades, muitas das vezes, a grade curricular é estática e pouco suscetível a alterações $^{5}$. Desse modo, atividades acadêmicas extracurriculares, tornam-se ferramentas essenciais para o estímulo e desenvolvimento de características como autonomia, autoconfiança, trabalho em grupo entre outras, que são fundamentais para sua prática futura como um agente de saúde. 
A oportunidade de aproximar o discente de práticas extracurriculares, permite que o mesmo execute seus conhecimentos teóricos científicos aprendidos no decorrer do seu processo de formação. Ademais, proporciona uma aprendizagem estimuladora, capaz de desenvolver habilidades e competências que vão desde a pesquisa à assistência. Nesse sentido, o contato com diferentes sistemas de saúde e o aprendizado sobre suas respectivas formas de organização e funcionamento configuram-se em uma valiosa oportunidade de aprofundamento da visão a respeito da saúde ${ }^{5}$.

\section{Considerações finais}

O ensino médico e o processo de aprendizagem na área da saúde são muito amplos e complexos, fazendo com que o ambiente universitário não consiga ofertar, fidedignamente, a vasta e heterogênea condição vista na prática clínica. Assim, as experiências reforçadas e praticadas além de tal escopo são de grande valia para a consolidação de uma formação sólida e rebuscada, condizente com a vida diária no campo profissional.

Com isso, pode-se afirmar que a prática dos estágios voluntários são ferramentas essenciais para o estudante de medicina produzir uma visão mais acurada da realidade clínica, não só fundamentando seu conhecimento teórico-prático pregresso, mas também obtendo novos olhares e aprendizados.

Outro aspecto a ser observado é o potencial das ligas acadêmicas e órgãos estudantis em condicionar melhores condições de aprendizado a seus ligantes. É possível observar que muitas instituições universitárias, hodiernamente, apresentam defasagem curricular ou, até mesmo, dificuldade de acesso a centros de saúde, fazendo com que haja possíveis faltas na formação acadêmica de discentes. Com a parceria entre LAOMAC, COBRALC e o hospital em questão, foi possível promover uma experiência prática de ensino, que não poderia ser facilmente fornecida pela rede local, demonstrando a indubitável importância das coligações acadêmicas para a formação técnica dos futuros profissionais.

Por fim, essa experiência permitiu sobrepujar os limites de uma prática clínica acadêmica, ampliando as fronteiras do aprendizado, alcançando novos ambientes e conquistando condições de uma formação cada vez mais ampla e humana.

\section{Referências}

1. Silva LASR. Oncologic surgery: a great challenge. Revista do Colégio Brasileiro de Cirurgiões, v. 43, n. 3, p. 139-140, jun. 2016. FapUNIFESP. http://dx.doi.org/10.1590/010069912016003012.

2. Sullivan $\mathrm{R}$, Alatise $\mathrm{OI}$, Anderson $\mathrm{BO}$, Audisio R, Autier P, Aggarwal A, et al. Global cancer surgery: delivering safe, affordable, and timely cancer surgery. The Lancet Oncology, v. 16, n. 11, p. 1193-1224, set. 2015. Elsevier BV. http://dx.doi.org/10.1016/s1470-2045(15)002235.

3. Tavares AP, Ferreira RA, França $E B$, Fonseca Júnior CA, Lopes GC, Dantas NGT, et al. Revista Brasileira de Educação Médica, v. 31, n. 3, p. 254-265, dez. 2007. FapUNIFESP. http://dx.doi.org/10.1590/s010055022007000300008.

4. Bastos MLS, Trajman A, Teixeira EG, Selig L, Belo MTCT. O papel das ligas acadêmicas na formação profissional. Jornal Brasileiro de Pneumologia, v. 38, n. 6, p. 803-805, dez. 2012. FapUNIFESP. http://dx.doi.org/10.1590/s180637132012000600018.

5. Ferreira IG, Carreira LB, Botelho NM. Mobilidade internacional na graduação em medicina: relato de experiência. Abcs Health Sciences, v. 42, n. 2, p. 115-119, 28 ago. 2017. NEPAS.

http://dx.doi.org/10.7322/abcshs.v42i2.1013.

6. Freire P. Pedagogia da autonomia: saberes necessários à prática educativa. 33a Ed. São Paulo: Paz e Terra; 2006.

7. Carvalho AM. Erasto Gaertner: a trajetória da instituição do passado à atualidade. Curitiba: Stampa News Comunicação; 2007. 
Endereço para Correspondência

João Marcos Gomes da Silva

Rua Getúlio 185 apt 401

Bairro: Todos os Santos, Rio de Janeiro, RJ

CEP: 20.775-000

e-mail: john_94@outlook.com

Recebido em 14/12/2020

Aprovado em 24/03/2021

Publicado em 15/06/2021 